УДК $339.138 \quad$ JEL M31

\section{Окольнишникова Ирина Юрьевна}

д-р экон. наук, ФГБОУ ВО «Государственный университет управления», г. Москва, Российская Федерация ORCID: 0000-0002-4958-8189 e-mail: okolnishnikova.i@mail.ru

\section{Сумарокова Екатерина \\ Викторовна}

канд. экон. наук, ФГБОУ ВО «Государственный университет управления», г. Москва, Российская Федерация ORCID: 0000-0001-8963-6774

e-mail: sumarokova@bk.ru

\section{Краснов Евгений}

Владимирович

канд. экон. наук, ФГБОУ ВО «Государственный университет управления», г. Москва, Российская Федерация ORCID: 0000-0003-4472-2091

e-mail:ev_krasnov@guu.ru

\section{IrinaYu. Okolnishnikova Dr. Sci. (Econ.), State University of Management, Moscow, Russia ORCID: 0000-0002-4958-8189 e-mail: okolnishnikova.i@mail.ru Ekaterina V. Sumarokova Cand. Sci. (Econ.), State University of Management, Moscow, Russia ORCID: 0000-0001-8963-6774 e-mail: sumarokova@bk.ru}

Evgenii V. Krasnov Cand. Sci. (Econ.), State University of Management, Moscow, Russia ORCID: 0000-0003-4472-2091

e-mail:ev_krasnov@guu.ru
DOI 10.26425/1816-4277-2021-9-66-73

\section{АНАЛИЗ КЛЮЧЕВЫХ ТЕНДЕНЦИЙ И ПУТЕЙ СОВЕРШЕНСТВОВАНИЯ МАРКЕТИНГОВОЙ ДЕЯТЕЛЬНОСТИ ОТЕЧЕСТВЕННЫХ ПРОИЗВОДИТЕЛЕЙ КОММУНАЛЬНОЙ ТЕХНИКИ}

\begin{abstract}
Аннотация. Представлены результаты маркетингового анализа рынка спецтехники для жилищно-коммунального хозяйства России. Проанализированы тенденции развития рынка, охарактеризована динамика продаж коммунальной техники и выявлены сегменты продуктового портфеля отечественных производителей. Изучены особенности развития двух ключевых продуктовых сегментов: снегоочистителей и снегопогрузчиков, а также мусоровозных машин. Обосновано, что они имеют высокий рыночный потенциал и объективные предпосылки для импортозамещения, однако нуждаются в совершенствовании маркетингового сопровождения. Авторами предложен и обоснован комплекс мер по совершенствованию маркетинговой деятельности, включающий развитие финансовых инструментов поддержки покупателей, расширение ассортиментной линейки, совершенствование стратегий дистрибуии, оптимизацию работы колиентров и развитие экспорта с использованием инструментов господдержки.
\end{abstract}

Ключевые слова: маркетинг, маркетинговая деятельность, маркетинговое исследование, маркетинговый анализ, маркетинг в сфере ЖКХ, маркетирование коммунальной техники, анализ рынка коммунальной техники, конкурентоспособность коммунальной техники, импортозамещение

Для цитирования: Окольнишникова И.Ю., Сумарокова Е.В., Краснов Е.В. Анализ ключевых тенденций и путей совершенствования маркетинговой деятельности отечественных производителей коммунальной техники//Вестник университета. 2021. № 9. С. 66-73.

\section{ANALYSIS OF KEY TRENDS AND WAYS TO IMPROVE THE MARKETING ACTIVITIES OF DOMESTIC MANUFACTURERS OF MUNICIPAL EQUIPMENT}

Abstract. The results of the marketing analysis of the market of special equipment for housing and communal services of Russia are presented. Market trends have been analysed, the sales dynamics of municipal machinery have been characterised and segments of the product portfolio of domestic manufacturers have been identified. The article analyzes the features of the development of two key product segments - the segment of snowplows and snow loaders, as well as the segment of garbage trucks. It is proved that they have a high market potential and objective prerequisites for import substitution, but they need to improve marketing support. The authors proposed and justified a set of measures to improve marketing activities, including development of financial instruments to support customers, expansion of the product line, improvement of distribution strategies, optimisation of call centers and the development of exports using state support tools.

Keywords: marketing, marketing activity, marketing research, marketing analysis, marketing in the field of housing and communal services, marketing of municipal equipment, analysis of the market of municipal equipment, competitiveness of municipal equipment, import substitution

For citation: Okolnishnikova I.Yu., Sumarokova E.V., Krasnov E.V. (2021) Analysis of key trends and ways to improve the marketing activities of domestic manufacturers of municipal equipment. Vestnik universiteta, no. 9, pp. 66-73. DOI 10.26425/1816-4277-2021-9-66-73

(С) Окольнишникова И.Ю., Сумарокова Е.В., Краснов Е.В., 2021.

Статья доступна по лицензии Creative Commons «Attribution» («Атрибуция») 4.0. всемирная (http://creativecommons.org/licenses/by/4.0/).

(c) Okolnishnikova I.Yu., Sumarokova E.V., Krasnov E.V., 2021.

This is an open access article under the CC BY 4.0 license (http://creativecommons.org/licenses/by/4.0/).

(c) (i) 


\section{Введение}

Эффективное функционирование коммунального хозяйства невозможно без специализированной техники для уборки улиц, очистки их от снега, вывоза мусора и т. д. Вместе с тем в регионах часто не хватает современных машин, а действующий парк устаревает. Часто отечественная коммунальная техника отстает от требований времени и не может стать элементом интеллектуальных транспортных систем, создание которых является актуальной задачей городов России. Корни обозначенных проблем во многом связаны с отсутствием системного маркетингового сопровождения жилищно-коммунальной техники, включая исследования, анализ и разработку путей ее продвижения.

\section{Постановка проблемы}

В настоящее время в региональных жилищно-коммунальных хозяйствах (далее - ЖКХ) чаще всего используется техника, собранная на базе шасси отечественных грузовиков. Вместе с тем данный сегмент машиностроения переживает период упадка в технологическом, инвестиционном и инновационном планах. При этом зарубежные аналоги коммунальной техники в большинстве своем недоступны российским ЖКХ в связи с их дороговизной. Это актуализирует задачу импортозамещения - создания отечественной конкурентоспособной техники, способной быть более экологичной и безопасной, чем импортная продукция. Решение данной задачи должно базироваться на результатах анализа ключевых тенденций и путей совершенствования маркетинговой деятельности отечественных производителей ЖКХ-техники.

\section{Источники и методы исследования}

В ходе изучения проблемы авторами проанализированы официальные интернет-ресурсы ведущих российских производителей коммунальной техники, предприятий машиностроения, а также зарубежных производителей машин и оборудования для ЖКХ. Также были изучены данные официальной статистики и показатели социально-экономического развития, представленные на порталах субъектов Российской Федерации - лидеров в сфере реализации программ развития жилищно-коммунального обслуживания населения.

При проведении исследования использованы общенаучные методы системного и сравнительного анализа, обобщения и синтеза.

\section{Анализ результатов исследования}

Отечественный рынок коммунальной грузовой автомобильной техники в целом можно охарактеризовать как высокоперспективный, что связано с его большой потенциальной емкостью. Официальная статистика свидетельствует, что в России насчитывается более 1100 городов, более 1200 поселков городского типа и свыше 150 тысяч населенных пунктов сельского типа [1]. При этом, согласно действующим в стране нормативам, только для содержания 100 км автодороги требуется от 35 до 43 единиц техники специального назначения [13]. Сюда следует отнести также необходимость регулярного вывоза твердых бытовых отходов и многие другие операции, для которых необходима спецтехника. Поэтому можно считать, что коммунальная техника имеет большое хозяйственное значение и данный рынок следует оценивать как потенциально емкий.

Другим аргументом, косвенно подтверждающим стабильно высокий спрос на рынке коммунальной техники, являются аналитические данные компании «АВТОСТАТ». Согласно им, объем рынка новых грузовых автомобилей в России уже в июле 2020 г. вернулся к докризисному уровню и до настоящего времени продолжает уверенно расти [12].

Устойчивое развитие сегмента коммунальной спецтехники российского производства, ключевым фактором развития которого являются госзакупки, подтверждает проведенный авторами анализ. Согласно статистике, ежегодно объем рынка коммунальной техники в стране увеличивается на 5-7 \% В 2018 г. он превысил 4 тысячи единиц, и к 2023 г. ожидается рост данного значения в 2,5 раза [8].

Почти половину рынка (более 49 \%) занимают машины, способные выполнять комплекс различных работ по содержанию дорог. Кроме них, в эксплуатации есть коммунальная техника узкого профиля: мусоровозы, ассенизаторы, снегоуборщики, поливочные машины и пр. [11]. При этом большинство муниципальных коммунальных служб укомплектовано устаревшими моделями - износ машинного парка варьируется 
в пределах от $50 \%$ до $65 \%$ [13]. Это еще более актуализирует проблему развития ассортиментной линейки машин отечественного производства, их грамотного позиционирования и продвижения.

Как показало проведенное исследование, в разрезе производителей рынок машин для коммунального хозяйства характеризуется доминированием продаж новой техники российского производства. Всего вниманию потребителей на данный момент представлено порядка 40 марок отечественной техники. При этом лидерами продаж являются Арзамасский завод коммунального машиностроения, Смоленский завод Комплексные Дорожные машины имени М. И. Калинина, Мценский завод коммунального машиностроения и Меркатор Калуга.

Вместе с тем на рассматриваемом рынке присутствуют и тревожные тенденции. Более всего, по мнению авторов, настораживает и требует внимания то, что удельный вес продаж техники российского производства демонстрирует тенденцию к постепенному сокращению, а зарубежной - напротив, к росту. Об этом свидетельствуют, в частности, текущие данные и прогнозы исследовательской компании Russian Automotive Market Research [9].

Преодоление выявленной негативной тенденции лежит, по мнению авторов, в плоскости расширения ассортимента техники для ЖКХ, повышения функционала и внедрения маркетинговых подходов к ценообразованию на рынке отечественной коммунальной техники.

Анализ состояния отечественного рынка коммунальной техники в разрезе субъектов Российской Федерации показывает, что более половины (54 \%) рынка российских спецмашин приходится на долю Центрального и Приволжского федеральных округов. Пятую часть рынка составляют Москва и Московская область. Третье место в региональном рейтинге и первое среди нестоличных субъектов Российской Федерации занимает Краснодарский край [11].

Рассматривая продуктовый портфель производителей отечественной техники для коммунального хозяйства, авторы выделили четыре основные группы продуктов:

- машины для уборки дорог;

- ассенизаторские и пр. машины;

- снегоочистители и снегопогрузчики;

- мусоровозы.

Исследование показало, что наибольший рыночный потенциал имеют машины для очистки дорог и придомовых территорий от снега, а также мусоровозы. Рассмотрим данные сегменты более подробно.

В настоящее время в России насчитывается 29 тысяч единиц мусоровозов, и их продажи демонстрируют стабильный рост. Агентство «АВТОСТАТ» подсчитало, что за девять месяцев 2019 г. объем рынка мусоровозов достиг 2,6 тысяч единиц, что на 93 \% больше, чем в предыдущий период [14].

Три четверти отечественного рынка мусоровозов занимают автомобили трех российских марок. Лидером рынка является КАМАЗ. Второе место занимает белорусский МАЗ, а замыкают тройку лидеров машины компаний группы ГАЗ. Среди иностранных марок лидерами продаж на российском рынке являются MAN, Scania и Isuzu.

Динамичное развитие рынка мусоровозов во многом объясняется стартовавшей в ряде субъектов Российской Федерации «мусорной реформой», которая ставит задачей создание прозрачной системы обращения с отходами и, как следствие, усиление контроля за компаниями, работающими в этой сфере.

Опрошенные авторами эксперты рынка ЖКХ отметили, что в ответ на усиление госконтроля компании, осуществляющие вывоз мусора, стали уделять более пристальное внимание надежности своего автопарка. Как следствие, начался и в настоящее время активно идет переоснащение ключевых «мусорных» операторов. Вслед за ними и остальные транспортировщики мусора начали поэтапно выводить из эксплуатации технику на базе старых ЗИЛов и ГАЗов, включая в перевозки более современные мусоровозы.

Вместе с тем, согласно экспертным оценкам, общая потребность обновления парка мусоровозов в стране составляет 8 тысяч единиц в год, тогда как отечественная автомобильная промышленность производит лишь около 2 тысяч, что еще более актуализирует проблему грамотного, системного маркетингового управления этим сегментом рынка - расширения ассортиментной линейки, увеличения производства, оптимизации ценовой политики.

Резюмируя сказанное, можно утверждать, что производство и реализация мусорных машин - один из сегментов отечественного рынка, где создан хороший задел для развития, наблюдается стабильно положительная динамика продаж, присутствует выраженный спрос на продукцию российского производства и готовность обслуживающих компаний и других операторов рынка ее приобретать. Тем самым, налицо объективные предпосылки для развития импортозамещения. 
Еще одним перспективным сегментом является сегмент снегопогрузчиков и снегоуборочных машин. Однако, данный рынок, как показало проведенное авторами исследование, имеет выраженную специфику и существенно отличается от предыдущего.

Прежде всего, российская снегоочистительная техника отличается существенно большим разнообразием. В данном сегменте практически каждый производитель реализует собственные подходы к ассортиментной политике и использует авторские инновационные разработки. При этом крупногабаритная снегоуборочная техника занимает лишь десятую часть рынка, оставляя простор для среднетяжелых и компактных машин. По оценкам специалистов, в настоящее время объем рынка снегоуборочной техники составляет примерно 160 тысяч машин [10].

Как и в предыдущем, в данном сегменте преобладает отечественная техника. Вместе с тем темпы прироста объемов российского рынка в последние годы были весьма скромными, демонстрируя тревожную тенденцию к снижению [10]. По мнению авторов, можно прогнозировать и дальнейшее замедление темпов роста, но при этом объем рынка с высокой степенью вероятности будет увеличиваться.

С нашей точки зрения, в настоящее время основным двигателем роста рынка снегоуборочной техники выступает необходимость модернизации устаревшего парка. При этом, по мнению опрошенных экспертов, тренд рынка - за внедрением многофункциональных машин, которые выполняют различные операции на протяжении всего года, без учета сезонности. Именно на такую технику наблюдается сегодня высокий спрос.

Проведенное исследование показало, что наиболее перспективной на рынке является коммунальная техника, производимая на базе шасси отечественных грузовых автомобилей, двух классов: тяжелая - с полной массой свыше 14 т; среднетоннажная - с массой от 8 т до 14 т [4].

При этом важно подчеркнуть, что в течение последних сегмент тяжелой техники растет на фоне относительной стагнации других ассортиментных предложений. Рассмотрим представленные выше ключевые сегменты рынка с точки зрения особенностей развития конкурентной ситуации на них.

В сегменте тяжелой техники с полной массой свыше 14 т основными конкурентами российских машин, как следует из проведенного анализа, являются производители стран дальнего зарубежья, осуществляющие импорт либо сборку на территории России.

Структура и динамика данного сегмента рынка за последние 10 лет показывает, что около 44 \% техники производится гигантом российского автопрома - КАМАЗ. Заметно отстают от него, с годами постепенно теряя свои рыночные доли, МАЗ и УРАЛ (6 \% и 5 \% соответственно). Среди зарубежной техники высокую, сопоставимую с КАМАЗ популярность имеют европейские марки. Сравнительно небольшая, но стабильная и сопоставимая с УРАЛом, доля рынка занята китайскими производителями (порядка 4 \%). Остальная тяжелая техника производства России, стран СНГ и дальнего зарубежья представлена незначительно [8; 15].

Существенно иная динамика выявлена на рынке среднетоннажной коммунальной техники полной массой от 8 т до 14 т. В данном сегменте, как показало исследование, свыше 70 \% рынка принадлежит российскому бренду ГАЗ, тогда как отечественный лидер грузового автомобилестроения КАМАЗ занимает лишь немногим более $4 \%$. Кроме того, в последние годы существенно сдал рыночные позиции МАЗ, допустивший падение рыночной доли с 10 \% в 2013 г. до 1 \% в настоящее время. Кроме того, в отличие от сегмента тяжелой техники, существенная доля рынка (порядка 15 \%) принадлежит маркам из Японии и Южной Кореи, тогда как европейские марки занимают малую долю, оцениваемую в 3 \% рынка. При этом китайские производители демонстрируют те же 4 \% рынка не только в «тяжелой», но и в «среднетяжелой» технике [8; 15].

Таким образом, анализ ключевых тенденций рынка коммунальной техники России позволяет утверждать, что это один из наиболее перспективных сегментов отечественного машиностроения, демонстрирующий внешне стабильное развитие и выраженный спрос на спецтехнику. Вместе с тем авторами выявлены тревожные тенденции, связанные, в первую очередь, с ослаблением рыночных позиций техники отечественных производителей. Это актуализирует важность совершенствования маркетинговой деятельности отечественных производителей техники.

\section{Выводы и рекомендации}

Одним из важнейших направлений маркетирования является, по мнению авторов, повышение клиентоориентированности базовых российских автопроизводителей, обеспечение гибкого и оперативного реагирования на запросы клиентов, повышение уровня потребительской удовлетворенности. Для этого, с точки 
зрения авторов, необходимо внедрить комплекс услуг, сопутствующих продаже, эксплуатации, обслуживанию и утилизации коммунальной техники.

Формирование конкурентоспособного коммерческого предложения может быть, по мнению авторов, достигнуто за счет развития ассортиментной линейки, в том числе многофункциональной уборочной техники. Благодаря обновленному и расширенному модельному ряду, отечественные производители смогут повысить удовлетворенность потребителей, успешно конкурируя с мировыми производителями и в перспективе завоевывая зарубежные рынки. Кроме того, необходима системная работа по доработке продуктов, основанная на отзывах операторов ЖКХ-рынка.

Важное значение для совершенствования системы продвижения коммунальной техники российского производства имеет, по мнению авторов, развитие финансовых инструментов. Для эффективного маркетирования необходимо сформировать сбалансированный портфель финансовых продуктов, ориентированных на приобретение техники по специальным финансовым предложениям, что повысит комфортность покупок. Основными инструментами маркетинговой политики отечественных производителей коммунальной техники в этой области должны, с точки зрения авторов, стать:

- применение системы стимулирования, в том числе развитой системы скидок в зависимости от объемов продаж и вида оплаты;

- использование взаимозачетных операций через субъекты товаропроводящей сети;

- развитие дилерской сети и создание региональных складов;

- внедрение программ трейд-ин;

- развитие лизинговых продуктов.

Рассмотрим некоторые из перечисленных направлений подробнее.

Важное значение, по мнению авторов, имеет развитие дилерской сети и совершенствование техник прямых продаж. Широкое развитие дилерской и сервисной сети позволит обеспечить максимальный охват регионов, а также повысить качество обслуживания и сервисного сопровождения за счет непрерывного улучшения деятельности и более полного удовлетворения требований ЖКХ [3; 5].

В рамках совершенствования политики дистрибуции важно, по мнению авторов, обеспечить комплексное сопровождение спецтехники для ЖКХ в течение всего срока ее службы посредством предложения спектра необходимых потребителю услуг:

- выгодных условий приобретения машин;

- сервисного обслуживания в гарантийный и послегарантийный периоды;

- консультационной поддержки потребителей;

- круглогодичных тест-драйвов;

- обучения и повышения квалификации обслуживающего ЖКХ-технику персонала;

- предоставления потребителям доступа (или оперативной поставки) к полному ассортименту запасных частей вне зависимости от региона;

- помощи в модернизации либо утилизации автомобиля.

Кроме того, важным преимуществом может стать сближение цен на спецтехнику, запчасти к ней, а также сервисные и лизинговые услуги для покупателей в разных регионах России. Это устранит ценовой дисбаланс и повысит привлекательность машин отечественного производства.

Большую роль в повышении доли рынка отечественной коммунальной техники может, по мнению авторов, сыграть внедрение программы трейд-ин, доступной как для юридических, так и для физических лиц. Считаем, что обмен техники для ЖКХ необходимо развивать как в формате «старый автомобиль в обмен на новый», так и в формате обмена подержанных грузовиков «старый автомобиль на восстановленный» либо «старый автомобиль на старый», что актуально в условиях низкой платежеспособности ЖКХ-операторов российских регионов.

Отметим, что средства, полученные за автомобиль по программе трейд-ин, могут быть направлены на приобретение нового автомобиля как по договору купли-продажи, так и в лизинг в качестве первоначального взноса. Именно лизинг в настоящее время становится все более важным фактором при принятии решения о приобретении спецтехники для нужд ЖКХ. По мнению авторов, лизинговые продукты отечественных производителей коммунальной техники должны включать в себя систему консультаций, льготного финансирования, а также модернизацию, замену и утилизацию автомобиля. 
Еще одним инструментом совершенствования маркетинговой деятельности отечественных производителей коммунальной техники является, по мнению авторов, развитие кол-центров. Они, работая постоянно, помимо привычных консультаций, должны давать информацию о наличии техники, необходимых документах, программах трейд-ин. Работа кол-центров в таком формате будет повышать осведомленность клиентов о бренде и экономить их время [6; 7]. А также клиент сможет выбрать подходящую для себя лизинговую программу.

Важное значение в рамках стимулирования продаж отечественных производителей коммунальной техники имеет, по мнению авторов, выход в новые сегменты рынков и, в первую очередь, деятельность по развитию экспорта. Экспортный потенциал спецмашин для ЖКХ российского производства должен базироваться на формировании их имиджа как современной интеллектуальной автотехники, способной быть более экологичной и безопасной, чем импортная продукция.

Вместе с тем необходимо учитывать и препятствующие выходу спецтехники российского производства на международный рынок барьеры. По оценке проекта «Стратегии развития экспорта автомобильной промышленности», барьеры для всех российских автопроизводителей таковы:

- высокая стоимость экспортной логистики;

- значительные удельные затраты на сертификацию продукции;

- таможенные барьеры, приводящие к завышению цен на 15-30% относительно стран-конкурентов;

- несовершенство налоговой системы для экспортных поставок;

- недостаточное развитие программ клиентского кредитования и страхования и др. [2].

Полностью соглашаясь с приведенным экспертным мнением, подчеркнем, что для развития экспорта коммунальной техники важно, по мнению авторов, активнее использовать инструменты государственной поддержки. В их числе:

- страхование сделок от коммерческих и политических рисков;

- субсидирование процентных ставок при экспортных поставках;

- участие в форумах, конференциях, деловых советах, выставках и т. д.

\section{Заключение}

Перечисленные меры позволят актуализировать импортозамещение, создав систему маркетингового управления и продвижения конкурентоспособной спецтехники для обеспечения нужд ЖКХ России.

\section{Библиографический список}

1. Информация о количестве населенных пунктов по субъектам Российской Федерации // Министерство финансов Российской Федерации [Электронный ресурс]. - Режим доступа: https://minfin.gov.ru/ru/document/?id_4=128341-informatsiya_o_ kolichestve_naselennykh_punktov_po_subektam_rossiiskoi_federatsii\#: :text=\%D0\% $\% 3 \% \mathrm{D} 0 \% \mathrm{BE} \% \mathrm{D} 1 \% 80 \% \mathrm{D} 0 \% \mathrm{BE} \% \mathrm{D} 0 \%$ B4\%D0\%B0.\%20\%D0\%9F\%D0\%BE\%D1\%81\%D0\%B5\%D0\%BB\%D0\%BA\%D0\%B8\%D0\%B3\%D0\%BE\%D1\%80\%D0 \%BE\%D0\%B4\%D1\%81\%D0\%BA\%D0\%BE\%D0\%B3\%D0\%BE\%20\%D1\%82\%D0\%B8\%D0\%BF\%D0\%B0.\%20\%D0\%A 1\%D0\%B5\%D0\%BB\%D1\%8C\%D1\%81\%D0\%BA\%D0\%B8\%D0\%B5\%20\%D0\%BD\%D0\%B0\%D1\%81\%D0\%B5\%D0\% BB\%D0\%B5\%D0\%BD\%D0\%BD\%D1\%8B\%D0\%B5,\%D0\%A4\%D0\%B5\%D0\%B4\%D0\%B5\%D1\%80\%D0\%B0\%D1\%8 6\%D0\%B8\%D0\%B8.\%201\%20111.\%201\%20221 (дата обращения: 01.08.2021).

2. Стратегия развития экспорта продукции автомобильной промышленности в Российской Федерации на период до 2025 года // Правительство России [Электронный ресурс]. - Режим доступа: http://static.government.ru/media/files/Gm80bGA Y20Pj1szROuP3rQVF82r3eJVc.pdf (дата обращения: 01.08.2021).

3. Барбье, Э.А., Сычев, М.В. Маркетинг в автобизнесе: сущность, значение и современная специфика // Вектор экономики. - 2019. - № 5 (35) [Электронный ресурс]. - Режим доступа: http://www.vectoreconomy.ru/images/publications/2019/5/ marketingandmanagement/Barbier_Sychev.pdf (дата обращения: 01.08.2021).

4. Воронов, А.А., Овчаренко, Н.А. Конкурентная среда российского грузового автомобилестроения: проблемы и перспективы // Практический маркетинг. - 2011. - № 1 (167). - С. 28-40.

5. Кенис, М.Ю., Сергиенко, Е.С. Особенности построения системы маркетинговых коммуникаций на автомобильном рынке // Знак: проблемное поле медиаобразования. -2018. - № 2 (28). - С. 136-141.

6. Писарева, Е.В. Принятие управленческих решений в контексте реализации концепции маркетинга взаимодействия // Конкурентоспособность в глобальном мире: экономика, наука, технологии. - 2017. - № 10 (57). - С. $623-625$. 
7. Федоров, В.А. Модель воздействия на потребителя «AIDA» в системе маркетинговых коммуникаций // Синергия Наук. - 2017. - № 11. - С. 238-242.

8. Анализ российского рынка коммунальной спецтехники // Перевозка 24: поиск грузов и транспорта [Электронный ресурс]. Режим доступа: https:/perevozka24.ru/pages/analiz-rossiyskogo-rynka-kommunalnoy-spectehniki (дата обращения: 01.08.2021).

9. Бутов, А.М. Рынок дорожно-строительных машин - 2021 год // НИУ ВШЭ; Центр развития [Электронный ресурс]. Режим доступа: https://www.hse.ru/data/2021/08/01/1423579556/\%D0\%A0\%D1\%8B\%D0\%BD\%D0\%BE\%D0\%BA_\%D0 \%B4\%D0\%BE\%D1\%80\%D0\%BE\%D0\%B6\%D0\%BD\%D0\%BE-\%D1\%81\%D1\%82\%D1\%80\%D0\%BE\%D0\%B8\%D1\%8 2\%D0\%B5\%D0\%BB\%D1\%8C\%D0\%BD\%D1\%8B\%D1\%85_\%D0\%BC\%D0\%B0\%D1\%88\%D0\%B8\%D0\%BD-2021.pdf (дата обращения: 01.08.2021).

10. Вашкевич, Е. Снегоуборочная техника: рост спроса очевиден // Igrader.ru - обзор рынка спецтехники, грузовиков [Электронный ресурс]. - Режим доступа: https://igrader.ru/difference/snegouborochnaya-tehnika-rost-sprosa-ocheviden/ (дата обращения: 01.08.2021).

11. Лобода, В., Тихонов, А. На долю Москвы и Подмосковья приходится более 20 \% рынка коммунальной техники // Аналитическое агентство Автостат [Электронный ресурс]. - Режим доступа: https://www.autostat.ru/news/38020/ (дата обращения: 01.08.2021).

12. Лузина, М. Российский рынок новых грузовых автомобилей в июле 2020 года // Аналитическое агентство Автостат [Электронный ресурс]. - Режим доступа: https://www.autostat.ru/press-releases/45102/ (дата обращения: 01.08.2021).

13. Раильченко, Ю. Рынок коммунальной техники // Техническое обслуживание гидравлических машин [Электронный pecypc]. - Режим доступа: https://www.tgms.ru/pages/rynok-kommunalnoy-tehniki/ (дата обращения: 01.08.2021).

14. Тимерханов, А. Рынок новых мусоровозов в России вырос вдвое [Электронный ресурс]. - Режим доступа: https://www. autostat.ru/news/42154/ (дата обращения: 01.08.2021).

15. Чупров, А. КАМАЗ в 2020 году увеличил продажи в России на 7 \% [Электронный ресурс]. - Режим доступа: https://www. autostat.ru/news/47510/ (дата обращения: 01.08.2021).

\section{References}

1. Information on the number of settlements in the constituent entities of the Russian Federation, Ministry of Finance of the Russian Federation. Available at: https://minfin.gov.ru/ru/document/?id_4=128341-informatsiya_o_kolichestve_naselennykh_punktov_po_subektam_ rossiiskoi_federatsiï: : text=0 $\mathrm{D} 0 \% 93 \% \mathrm{D} 0 \% \mathrm{BE} \% \mathrm{D} 1 \% 80 \% \mathrm{D} 0 \% \mathrm{BE} \% \mathrm{D} 0 \% \mathrm{~B} 4 \% \mathrm{D} 0 \% \mathrm{~B} 0 . \% 20 \% \mathrm{D} 0 \% 9 \mathrm{~F} \% \mathrm{D} 0 \% \mathrm{BE} \% \mathrm{D} 1 \% 81 \% \mathrm{D} 0 \% \mathrm{~B} 5 \% \mathrm{D} 0 \% \mathrm{~B}-$ B\%D0\%BA\%D0\%B8\%D0\%B3\%D0\%BE\%D1\%80\%D0\%BE\%D0\%B4\%D1\%81\%D0\%BA\%D0\%BE\%D0\%B3\%D0\%BE\%20 $\% \mathrm{D} 1 \% 82 \% \mathrm{D} 0 \% \mathrm{~B} 8 \% \mathrm{D} 0 \% \mathrm{BF} \% \mathrm{D} 0 \% \mathrm{~B} 0 . \% 20 \% \mathrm{D} 0 \% \mathrm{~A} 1 \% \mathrm{D} 0 \% \mathrm{~B} 5 \% \mathrm{D} 0 \% \mathrm{BB} \% \mathrm{D} 1 \% 8 \mathrm{C} \% \mathrm{D} 1 \% 81 \% \mathrm{D} 0 \% \mathrm{BA} \% \mathrm{D} 0 \% \mathrm{~B} 8 \% \mathrm{D} 0 \% \mathrm{~B} 5 \% 20$ $\% \mathrm{D} 0 \% \mathrm{BD} \% \mathrm{D} 0 \% \mathrm{~B} 0 \% \mathrm{D} 1 \% 81 \% \mathrm{D} 0 \% \mathrm{~B} 5 \% \mathrm{D} 0 \% \mathrm{BB} \% \mathrm{D} 0 \% \mathrm{~B} 5 \% \mathrm{D} 0 \% \mathrm{BD} \% \mathrm{D} 0 \% \mathrm{BD} \% \mathrm{D} 1 \% 8 \mathrm{~B} \% \mathrm{D} 0 \% \mathrm{~B} 5, \% \mathrm{D} 0 \% \mathrm{~A} 4 \% \mathrm{D} 0 \% \mathrm{~B} 5 \% \mathrm{D} 0 \%$ B4\%D0\%B5\%D1\%80\%D0\%B0\%D1\%86\%D0\%B8\%D0\%B8.\%201\%20111.\%201\%20221 (accessed 01.08.2021).

2. Strategy for the Development of Exports of Automotive Products in the Russian Federation for the Period up to 2025, The Russian Government. Available at: http://static.government.ru/media/files/Gm80bGAY20Pj1szROuP3rQVF82r3eJVc.pdf (accessed 01.08.2021). (In Russian).

3. Barbier E.A., Sychev M.V. Marketing in autobusiness: essence, value and modern specificity, Vektor ekonomiki, 2019, no. 5 (35). Available at: http://www.vectoreconomy.ru/images/publications/2019/5/marketingandmanagement/Barbier_Sychev.pdf (accessed 01.08.2021). (In Russian).

4. Voronov A., Ovcharenko N. Competition environment in Russian truck industry: problems and prospects, Practical Marketing, 2011, no. 1 (167), pp. 28-40. (In Russian).

5. Kenis M.Yu., Sergienko E.S. Peculiarities of construction of marketing communications system in the automotive market, Znak: problemnoe pole nediaobrazovanija, 2018, no. 2 (28), pp. 136-141. (In Russian).

6. Pisareva E.V. Management decision-making in the context of implementing the concept of interaction marketing, Competitiveness in the Global World: Economics, Science, Technologies, 2017, № 10 (57), pp. 623-625. (In Russian).

7. Fedorov V.A. The "AIDA" model in the system of marketing communications, Sinergiya Nauk, 2017, no. 11, pp. 238-242. (In Russian).

8. Analysis of the Russian market of communal special equipment, Perevozka 24: Search for Freight and Transport. Available at: https://perevozka24.ru/pages/analiz-rossiyskogo-rynka-kommunalnoy-spectehniki (accessed 01.08.2021). (In Russian).

9. Butov A.M. Road-building machinery market - 2021, Higher School of Economics, Centre of Development Institute. Available at: https://www.hse.ru/data/2021/08/01/1423579556/\%D0\%A0\%D1\%8B\%D0\%BD\%D0\%BE\%D0\%BA_\%D0\%B4\%D 0\%BE\%D1\%80\%D0\%BE\%D0\%B6\%D0\%BD\%D0\%BE-\%D1\%81\%D1\%82\%D1\%80\%D0\%BE\%D0\%B8\%D1\%82\%D0\% 
B5\%D0\%BB $\%$ D1\%8C $\%$ D0\%BD $\%$ D1\%8B $\%$ D $1 \% 85$ \%D0\%BC\%D0\%B0\%D1\%88\%D0\%B8\%D0\%BD-2021.pdf (accessed 01.08.2021). (In Russian).

10. Vashkevich E. Snow removal equipment: demand growth is obvious, Igrader.ru-Overview of Special Equipment and Trucks Market. Available at: https://igrader.ru/difference/snegouborochnaya-tehnika-rost-sprosa-ocheviden/ (accessed 01.08.2021). (In Russian).

11. Loboda V., Tikhonov A. The share of Moscow and the Moscow region accounts for more than $20 \%$ of the market of municipal equipment, Autostat Analytic Agency. Available at: https://www.autostat.ru/news/38020/ (accessed 01.08.2021). (In Russian).

12. Luzina M. Russian market of new trucks in July 2020, Autostat Analytic Agency. Available at: https://www.autostat.ru/press-releases/45102/ (accessed 01.08.2021). (In Russian).

13. Railchenko Y. Market of municipal equipment, Maintenance of Hydraulic Machines. Available at: https://www.tgms.ru/pages/ rynok-kommunalnoy-tehniki/ (accessed 01.08.2021). (In Russian).

14. Timerkhanov A. The market of new garbage trucks in Russia has doubled, Autostat Analytic Agency. Available at: https://www. autostat.ru/news/42154/ (accessed 01.08.2021). (In Russian).

15. Chuprov A. KAMAZ in 2020 increased sales in Russia by 7 \%, Autostat Analytic Agency. Available at: https://www.autostat.ru/ news/47510/ (accessed 01.08.2021). (In Russian). 